\title{
A STUDY OF CLINICAL AND LABORATORY PROFILE OF PATIENTS WITH SYSTEMIC LUPUS ERYTHEMATOSUS AT A TERTIARY CARE CENTER IN WESTERN INDIA
}

\section{Dr Seema Sharma \\ Dr Shivani A Patel \\ Dr Shivam N \\ Shah* \\ Dr Mauli P Vora}

Assistant Professor, Department of General Medicine, CHA.

Associate Professor, Department of General Medicine, CHA.

Second year resident, Department of General Medicine, CHA.*Corresponding Author

ABSTRACT

Aim: To study the clinical and laboratory profile of patients having systemic lupus erythematosus (SLE) at Civil Hospital, Ahmedabad.

SLE is an autoimmune multisystem disease which mainly affects young females in their child bearing age leading to decreased productivity and increased economic burden

Methods: -Type of study: Cross sectional study. Patients fulfilling revised American College of Rheumatology criteria (1982) for SLE were included in the study. Detailed history, clinical examination and laboratory results of the patients were noted. Data analysis was carried out using Statistical Package for Social Sciences.

Results: 25 patients were enrolled in the study. Females (84\%) were more commonly affected, maximum patients being in the age group of $20-$ 30 years. Arthritis was amongst the commonest initial manifestation (84\%) followed by anemia (76\%). Other manifestations included involvement of Renal, Cardiopulmonary, Dermatologic and Nervous System. ANA antibody was found positive in all patients while anti dsDNA was positive in $80 \%$ patients.

Conclusion: The incidence of anemia and lupus nephritis was higher in our study as compared to other studies. Early intervention and close follow up is vital to prevention of morbidity and mortality. Arthritis and Anemia were amongst the most common clinical features.

\section{KEYWORDS :}

\section{INTRODUCTION}

SLE is a disease that mostly affects young females in reproductive age group, which constitutes economically, the most productive population, hence, early diagnosis and screening can help reduce mortality, morbidity and improve overall prognosis of the disease ${ }^{[8]}$. Considerable variation has been observed regarding various clinical manifestations of SLE among various ethnic groups as well as various geographic regions. In most patients' autoantibodies are present for few years before first clinical symptoms appear ${ }^{[10]}$. Hence this study was undertaken at Civil Hospital, Ahmedabad, aimed to identify various clinical manifestations and laboratory parameters of patients with SLE.

Systemic lupus erythematosus (SLE) is an autoimmune disease in which autoantibodies and immune complexes get deposited in various organs, tissues, and cells causing widespread damage due to complement activation and inflammation at local sites of immune complex deposition. More than 100 autoantibodies have been found in the sera of patients with SLE. Genetic factors superimposed on certain environmental factors play a very pivotal role in manifesting abnormal immunological response ${ }^{[11]}$

\section{MATERIALAND METHODS}

All patients satisfying the revised American College of Rheumatology criteria (1982) for SLE were included in the study. Clinical assessment included detailed medical history, presenting chief complaints, duration of disease, assessment of different systems, i.e., cutaneous, musculoskeletal, nervous, cardiopulmonary, hepatic and Gastrointestinal systems. Routine investigations including Complete Blood Count, Erythrocyte Sedimentation Rate, urine routine microscopy study, 24-hour urine protein excretion study, renal function tests, liver function tests, random blood glucose, lipid profile, 12-lead ECG, chest X-ray 2D-Echocardiography, ultrasound examination, CT scan (brain) was done wherever required. Immunological investigations like anti-nuclear antibody (ANA), and complete profile including anti-dsDNA, rheumatoid factor (RF), antihistone antibody, anti-Smith antibody, anti RNP antibody were done in all patients. All patients with renal involvement were subjected to renal biopsy. Data was analyzed using SPSS (Statistical Package for Social Sciences)

\section{RESULTS:}

Table I: Age and gender wise distribution of patients

\begin{tabular}{|l|c|c|c|}
\hline & & \multicolumn{2}{|c|}{ Gender Distribution } \\
\hline & Present study & Age Group & No of patients $(\mathrm{n}=25)$ \\
\hline Female & $21(84 \%)$ & $21-30 \mathrm{yrs}$ & 13 \\
\hline & & $31-40 \mathrm{yrs}$ & 5 \\
\hline & & $41-50 \mathrm{yrs}$ & 2 \\
\hline Male & $4(16 \%)$ & $21-30 \mathrm{yrs}$ & 1 \\
\hline & & $31-40 \mathrm{yrs}$ & 2 \\
\hline & & $41-50 \mathrm{yrs}$ & 1 \\
\hline
\end{tabular}

Table 2: Duration of symptom onset to presentation

\begin{tabular}{|l|l|}
\hline $\begin{array}{l}\text { Duration between symptom onset to } \\
\text { seeking medical attention (months) }\end{array}$ & No of patients affected \\
\hline $0-6$ & $2(8 \%)$ \\
\hline $6-12$ & $2(8 \%)$ \\
\hline $12-18$ & $10(40 \%)$ \\
\hline $18-24$ & $11(44 \%)$ \\
\hline
\end{tabular}

25 patients were studied, of which 21 were females and 4 were males. Male to female ratio was 1: 5 . The mean age at onset of disease was 28 years. Mean age of onset in male patients was 35 years and that in female patients were 27 years. 70 per cent of the patients fell in the age group of 20 - 30 years in age. Mean duration of disease onset to seeking medical attention was 16 months.

Table 3: Clinical Profile in present study

\begin{tabular}{|l|l|l|l|}
\hline A) Hematological & No. of cases & E)Cardiopulmonary & $\begin{array}{l}\text { No. of } \\
\text { cases }\end{array}$ \\
\hline Anemia & $\begin{array}{l}19 \\
(76 \%)\end{array}$ & Pleural effusion & $4(16 \%)$ \\
\hline Leucopenia & $4(16 \%)$ & Pericardial effusion & $1(4 \%)$ \\
\hline Thrombocytopenia & $2(8 \%)$ & F) Renal & \\
\hline B) Musculoskeletal & & Proteinuria + & $2(8 \%)$ \\
\hline Polyarthritis & $9(36 \%)$ & Proteinuria ++ & $8(32 \%)$ \\
\hline Oligoarthritis & $4(16 \%)$ & Proteinuria +++ & $6(24 \%)$ \\
\hline Monoarthritis & $8(32 \%)$ & Proteinuria ++++ & $5(20 \%)$ \\
\hline C) Mucocutaneous & & Hematuria & $18(72 \%)$ \\
\hline $\begin{array}{l}\text { Photosensitivity } \\
\text { (malar Rash) }\end{array}$ & $9(36 \%)$ & G) Neurologic & \\
\hline Discoid rash & $2(8 \%)$ & Seizures & $2(8 \%)$ \\
\hline Oral ulcers & $2(8 \%)$ & & \\
\hline Vasculitic rash & $1(4 \%)$ & & \\
\hline
\end{tabular}


D) Menstrual Irregularity Oligomenorrhea/ amenorrhea Menorrhagia

\begin{tabular}{|l|l|l|l|}
\hline & & & \\
\hline $6(36 \%)$ & & \\
\hline $6(24 \%)$ & & \\
\hline
\end{tabular}

Table 4: Immunological Profile in patients of SLE

\begin{tabular}{|l|l|}
\hline Immunological Profile & \% Patients having antibody \\
\hline Antibody & $25(100 \%)$ \\
\hline ANA & $20(80 \%)$ \\
\hline Anti-dsDNA & $3(12 \%)$ \\
\hline Anti-histone & $4(16 \%)$ \\
\hline Anti-Smith & $2(8 \%)$ \\
\hline Anti RNP & $6(24 \%)$ \\
\hline Anti La (SS-b) &
\end{tabular}

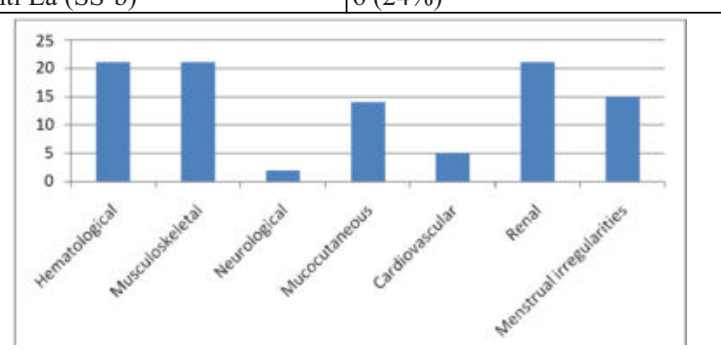

Figure 1. ClinicalManifestationsof SLE

Anemia was seen in 19 patients $(76 \%), 10$ of whom had Coombs positive autoimmune hemolytic anemia, with rest of them having normocytic or microcytic anemia. Leucopenia (total count $<4000$ per $\mathrm{cu} \mathrm{mm}$ ) and thrombocytopenia (platelets $<1$.5lakh per cu $\mathrm{mm}$ ) was also found in $4(16 \%)$ and $2(8 \%)$ patients respectively.

Arthritis was the commonest initial manifestation (21 patients affected). Symmetrical, nonerosive polyarthritis was noted in 9 patients $(36 \%)$ and oligoarthritis in 4 patients $(16 \%)$

Dermatologic manifestations in the form photosensitivity, oral ulcers, vasculitic rash, and discoid rash were noted in 14 patients $(76 \%)$.

Menstrual irregularities in the form of oligomennorhea/ amenorrhea was found in 9 patients while menorrhagia was found in 6 patients $(24 \%)$.

Cardio-pulmonary involvement was noticed in 5 patients $(20 \%)$. Pleural effusion was present in 4 patients, 2 of them had pericardial rub. 1 patient had pericardial effusion without signs of tamponade.

Neurological involvement was noted in 2 patients $(8 \%)$, presenting with Generalized Tonic Clonic seizures.

Table 5: Stages of Lupus Nephritis in patients

\begin{tabular}{|l|l|}
\hline Stage of Lupus Nephritis & No. of Patients (n=18) \\
\hline Stage I (Minimal mesangial) & 7 \\
\hline Stage II (Mesangial proliferative) & 2 \\
\hline Stage III (focallupus nephritis) & 3 \\
\hline Stage IV (diffuselupus arthritis) & 3 \\
\hline Stage V (Membranous LN) & 1 \\
\hline Stage VI (Advanced sclerosing LN) & 2 \\
\hline
\end{tabular}

Renal involvement was noted in 18 patients, and all of them were subjected to renal biopsy. Proteinuria ( $>0.2 \mathrm{gm} / 24$ hours) was seen in all 18 patients. Elevated serum creatinine $(>1.5 \mathrm{mg} / \mathrm{dl})$ was noted in 9 patients. Minimal Mesangial Glomerulonephritis (WHO grade 1) was the most commonly seen histological pattern, seen in 7 patients $(28 \%)$. 2 of them had Sclerosing glomerulonephritis (8\%).

Table 6: Antibody profile in different stages of Lupus Nephritis

\begin{tabular}{|l|c|c|c|c|c|c|}
\hline \multicolumn{7}{|c|}{ Frequency distribution of antibodies according to stage of } \\
Lupus Nephritis \\
\hline & ANA & dsDNA & $\begin{array}{c}\text { Anti } \\
\text { histone }\end{array}$ & $\begin{array}{c}\text { Anti } \\
\text { Smith }\end{array}$ & $\begin{array}{c}\text { Anti } \\
\text { RNP }\end{array}$ & $\begin{array}{c}\text { Anti La } \\
\text { (SS B) }\end{array}$ \\
\hline Stage 1 & 4 & 3 & 1 & 2 & & \\
\hline Stage 2 & 5 & 4 & & & & \\
\hline Stage 3 & 4 & 3 & & & 2 & 1 \\
\hline Stage 4 & 1 & 1 & & & & \\
\hline Stage 5 & 1 & 1 & & & & \\
\hline Stage 6 & 2 & 2 & & & & \\
\hline \hline
\end{tabular}

Maximum patients presented in stage 1 of Lupus Nephritis i.e. Minimal Mesangial Glomerulonephritis (28\%). Most common antibody detected in patients of lupus nephritis was ANA $(100 \%)$ followed by Anti dsDNA(100\%).

\section{DISCUSSION}

In the present study, SLE was found more commonly in females (84\%); the mean age being 28 years. Our observed that the male:female ratio was 1:4 with maximum patients in 20-30 year age group. These findings were consistent with study carried out by Binoy et al in which out of 75 patients evaluated, 70 were females ${ }^{[2]}$

In our study, the most common clinical feature was Arthritis (84\% patients), which was followed by Anemia (76\%). This is comparable to study by Madhavan where arthritis was the most commonly found clinical feature $(68.5 \% \text { patients affected })^{[6]}$. In our study polyarthritis was the most common feature, affecting 7-8 joints.

In our study, common hematological manifestations were Anemia (76\%), (normocytic normochromic). Thiswas higher as compared to other studies, like Saigal at el $(6.7 \%)$ and Binoy at el $(1.3 \%)^{[2]}$.In the present study,thrombocytopenia was noted in $4 \%$ which is similar to a study by Saigal in which $3.3 \%$ patients had thrombocytopenia ${ }^{[4]}$.In SLE, anemia occurs due to immune complex mediated complement activation, which causes hemolysis

Photosensitivity was the most frequent cutaneous manifestation in all patients (36\% patients). This is comparable to the study by Malaviya et al in which $36 \%$ patients had photosensitivity while in Kosaraju at el $27.08 \%$ patients had photosensitivity ${ }^{[3][7]}$.

Serositis manifesting as pleuritis (16\%), pericardial effusion (4\%) was found inpatients of SLE in our study.

Renal featuresin the form of proteinuria in the range of $>300 \mu \mathrm{g} /$ day was found in $72 \%$ patients which was significantly higher as compared to Saigal at el 2003, $(13.3 \%)$ and Malaviya $1985,(8 \%)^{[4][7]}$. All of these patients were subjected to renal biopsy. Renal biopsy results revealed Stage 1 Lupus Nephritis (minimal mesangial) in maximum (28\%) patients. ANA was the most frequent autoantibody associated with this stage.Immunologically, apart from ANA, Anti ds DNA was the second most commonly found to be associated antibody with the lupus nephritis in our patients.

Neurological features were found in $4 \%$ patients in our study, whereas it was 3.3\% in Saigal et al and 3.7 in Madhavan et a ${ }^{[4][6]}$.

\section{CONCLUSION}

In this study, the prevalence of SLE was found to be more in females compared to males, mean duration of symptom onset to presentation at tertiary care center was 16 months. Arthritis was the most common manifestation followed by Hematologic (anemia), renal (Nephritis). Hematological (Anemia) and Renal features were found to be higher in our study. ANA was the most common antibody followed by anti dsDNA. In patients with Lupus Nephritis, ANA was the most common antibody followed by anti dsDNA. Amongst those patients having Lupus Nephritis, maximum were found in WHO stage 1 (Minimal Mesangial Glomerulo Nephritis). Arthritis, Anemia and Lupus Nephritis affected a significant proportion of young females, which leads to decreased productivity, impairment of daily activities and increase in economic burden. Hence high index of suspicion in patients with symptom complex suggestive of SLE can lead to early diagnosis and detection of complications.

\section{REFERENCES}

1. Hsieh $\mathrm{SC}, \mathrm{Yu} \mathrm{Cl}$. Autoantibody profiling in systemic lupus erythematosus. CurrBiomark Find2013; 3:55-65.

2. Binoy JP Muhammed F Kumar N, Razia MV. Clinical profile of systemic lupus erythematosus in North Kerala. J Indian Rheumatol Assoc 2003;11-94-7

3. Kosaraju K, Shenoy S, Suchita U. A cross sectional hospital-based study of clinical and (1) autoantibody profic

4. Saigal R, Kansal A, Mittal M, Singh Y, MahariaHR, Juneja M. Clinical profile of systemic lupus erythematosus at a tertiary care centre in Western India. J Indian Acad Clin Med 2011:13:27-32

5. Paul BJ, Muhammed Fassaludeen, Nandakumar, Razia MV. Clinical profile of Systemi Lupus Erythematosus in Northern Kerala. J Indian Rheumatol Assoc 2003; 11:94-7

6. Madhavan R et al. Systemic Lupus Erythematosus: The Madras Experience. J Assoc Phys India 1988; 36: 481-4

7. Malaviya AN, Singh RR, Kumar A et al. SLE in Northern India. A review of 329 cases. J Assoc Phys India 1988; 36: 476-80.

8. https://www.ncbi.nlm.nih.gov/pmc/articles/PMC2891868/

9. https://www.ncbi.nlm.nih.gov/pmc/articles/PMC1798007

10. https://www.ncbi.nlm.nih.gov/pmc/articles/PMC3391953/

11. Kelley's Textbook on Rheumatology 